\title{
Androgen receptor promotes gastric cancer cell migration and invasion via AKT-phosphorylation dependent upregulation of matrix metalloproteinase 9
}

\author{
Bao-gui Zhang ${ }^{1, *}$,Tao Du ${ }^{1,2, *}$, Ming-de Zang ${ }^{1}$,Qing Chang ${ }^{1}$, Zhi-yuan Fan ${ }^{1}$, Jian-fang \\ $\mathrm{Li}^{1}$, Bei-qin Yu ${ }^{1}$, Li-ping Su${ }^{1}$, Chen $\mathrm{Li}^{1}$, Chao Yan ${ }^{1}$, Qin-long Gu ${ }^{1}$, Zheng-gang Zhu ${ }^{1}$, \\ Min Yan' ${ }^{1}$ and Bingya Liu ${ }^{1}$ \\ 1 Shanghai Key Laboratory of Gastric Neoplasms, Department of Surgery, Shanghai Institute of Digestive Surgery, Ruijin \\ Hospital, Shanghai Jiao Tong University School of Medicine, Shanghai, China \\ 2 Department of Surgery, Shanghai East Hospital, Tongji University School of Medicine, No 150 Jimo Road, Shanghai, China \\ * These authors contributed equally to this work \\ Correspondence to: Bingya Liv, email: byliu@sjtu.edu.cn \\ Min Yan, email: ym10299@163.com \\ Keywords: Androgen receptor, AKT, MMP9, Gastric cancer
}

Received: August 14, $2014 \quad$ Accepted: September 24, $2014 \quad$ Published: September 25, 2014

This is an open-access article distributed under the terms of the Creative Commons Attribution License, which permits unrestricted use, distribution, and reproduction in any medium, provided the original author and source are credited.

\section{ABSTRACT}

Androgen receptor (AR) plays an important role in many kinds of cancers. However, the molecular mechanisms of AR in gastric cancer (GC) are poorly characterized. Here, we investigated the role of AR in GC cell migration, invasion and metastatic potential. Our data showed that AR expression was positively correlated with lymph node metastasis and late TNM stages. These findings were accompanied by activation of AKT and upregulation of matrix metalloproteinase 9 (MMP9). AR overexpression induced increases in GC cell migration, invasion and proliferation in vitro and in vivo. These effects were attenuated by inhibition of AKT, AR and MMP9. AR overexpression upregulated MMP9 protein levels, whereas this effect was counteracted by AR siRNA. Inhibition of AKT by siRNA or an inhibitor (MK-2206 2HC) decreased AR protein expression in both stably transfected and parental SGC-7901 cells. Luciferase reporter and chromatin immunoprecipitation assays demonstrated that AR bound to the AR-binding sites of the MMP9 promoter. In summary, AR overexpression induced by AKT phosphorylation upregulated MMP9 by binding to its promoter region to promote gastric carcinogenesis. The AKT/AR/MMP9 pathway plays an important role in GC metastasis and may be a novel therapeutic target for GC treatment.

\section{INTRODUCTION}

Gastric cancer (GC), hepatocellular carcinoma (HCC), and pancreatic cancer are all male-predominant cancers [1-3]. In view of this remarkable gender disparity, some studies have explored the importance of the androgen receptor (AR) axis in these cancers $[3,4]$. The results have demonstrated that aberrant expression or functions of AR are major contributors to the sex-related disparity in these cancers, which indicated the strong oncogenic properties of AR.

$\mathrm{GC}$ is the fourth most common cancer worldwide and more common in developing countries, and the incidence of $\mathrm{GC}$ is higher in males than in females with a ratio of 2:1 [1]. Elucidation of the factors causing the sexrelated disparity of GC may be important to reveal critical pathways in gastric carcinogenesis. Here, we hypothesized that AR may be responsible for such disparity.

$\mathrm{AR}$, also known as NR3C4 (nuclear receptor subfamily 3 , group C, member 4), belongs to a family of nuclear receptors that act as transcription factors. Many studies have described the functions of AR in both androgen-dependent and -independent manners [2]. For example, AR overexpression promotes HCC 
tumorigenicity which may explain the gender disparity of HCC $[5,6]$. However, little is known about the mechanism of the disparity in GC. In 1990, Wu demonstrated the presence of AR in GC tissues [7]. Subsequently, some reports have shown the expression of $\mathrm{AR}$ in the stomach [8-10]. The significance of AR has been studied for the prognosis of $\mathrm{GC}$, which reported that AR-negative patients show significantly better survival than AR-positive patients. [11]. Besides, An increasing body of evidence from in vitro and in vivo studies has shown that AR not only mediates the effects of androgen but also functions as an oncoprotein by interacting with other molecules implicating the proliferation and metastasis of cancer cells $[12,13]$.

Moreover, AR is functionally associated with a broad range of oncogenic signaling pathways. Ha et al found that AR levels are regulated by the AKT [14]. Activation of AKT causes downstream effects such as increases in coactivator binding and chromatin modifications associated with an increase in AR transcriptional output [15]. AKT, also known as protein kinase $\mathrm{B}$, is crucial for regulation of cell proliferation, differentiation, apoptosis, and migration $[16,17]$. It is well established that the AKT/P-AKT pathway plays an important role in many kinds of cancers including GC $[18,19]$.

Recent data have demonstrated that AR is closely related to the development of various types of human cancer by elevating cell migration and invasion in response to various stimuli including inflammatory factors [20]. It is also well known that extracellular matrix (ECM) degradation by matrix metalloproteinases (MMPs) is critical for tumor invasion and metastasis [21]. In GC, MMP2 and MMP9 play an important role in tumor progression, and the degree of MMP2 and MMP9 expression has been shown to correlate with the tumor grade and stage [22]. However, the effect of AR on MMP2 and MMP9 expression in GC is poorly understood.

Here, we investigated AR expression, its relationship to clinicopathological features and P-AKT/MMP9 expression in GC tissues by immunohistochemistry (IHC). Additionally, the effect of AR on the invasion and metastasis of GC cells was examined in vitro and in vivo. Finally, we characterized the molecular mechanism by which AR mediates the metastatic potential of GC cells.

\section{RESULTS}

\section{AR expression in GC and its correlation with clinicopathological parameters}

To explore the role of AR in GC, we performed IHC to analyze the protein expression of $40 \mathrm{GC}$ tissue samples. We identified 15 and $25 \mathrm{GC}$ tissue samples that were positive and negative for AR, respectively.
It has been previously reported that dysregulated AR is an independent unfavorable prognostic factor in GC with a positivity rate of $20 \%$ [11], the authors' results are in accordance with the reported data (15 out of 40 ).
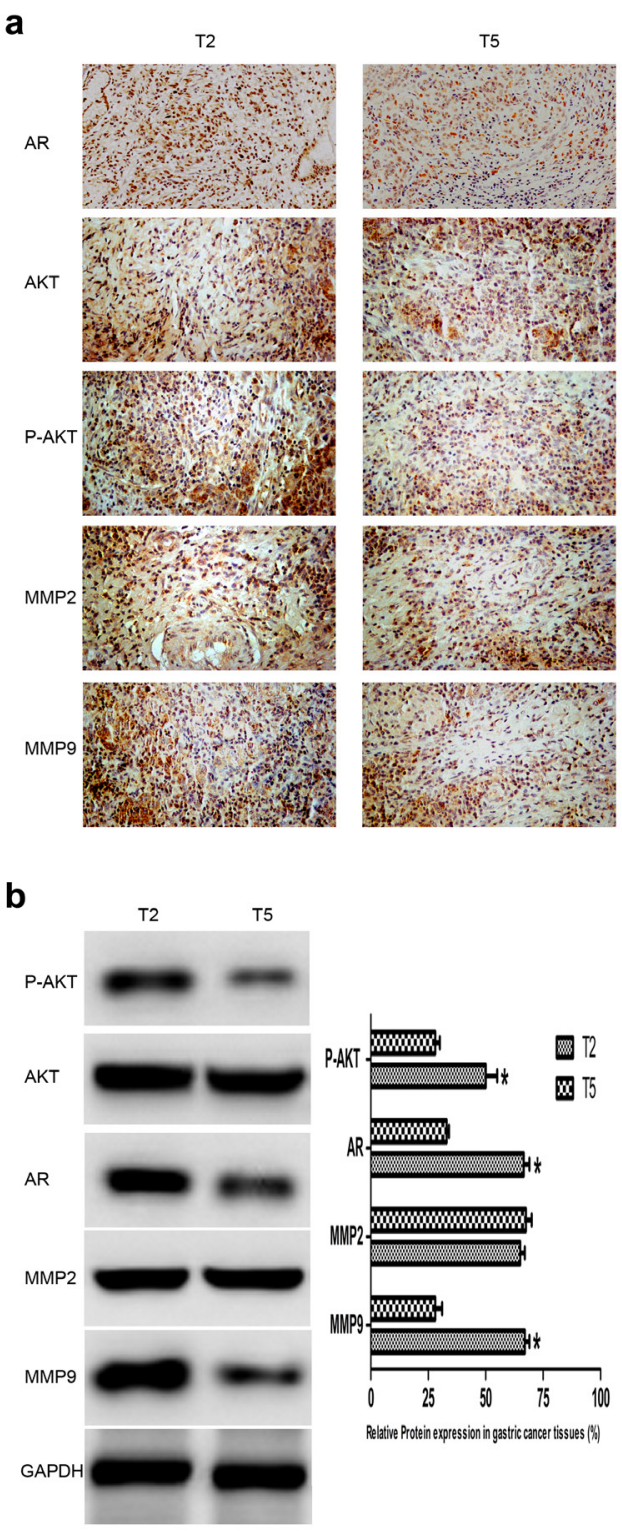

Fig.1: Expression of AR, P-AKT, MMP2, and MMP9 in GC tissues. (a) AR, P-AKT, MMP2 and MMP9 protein expression in GC tissues detected by IHC. T2 and T5 were cancer tissues deprived from individuals with or without lymph node metastasis (late or early TNM stage) as shown in Table 1, and they represented cancer tissues with positive and negative expression of AR, respectively. AR, mainly located in nucleus, AKT/P-AKT/MMPs mainly located in cytoplasm and nucleus. (b) Left: AR, P-AKT, MMP2 and MMP9 protein expression in GC tissues detected by WB. Right: densitometric analysis of the bands obtained for each signal. The P-AKT, AR and MMP9 protein levels were higher in $\mathrm{T} 2$ than that in T5. Results are expressed as relative expression to control samples. Data are the mean of three independent experiments $\pm \mathrm{SD}(* \mathrm{P}<0.05)$ (original magnification, $\times 200$ ). 
Table 1: Relationship between AR expression level and clinicopathologic parameters

\begin{tabular}{|c|c|c|c|c|}
\hline Clinicopathologic Parameters & Numbers (n) & Positive & Negative & $P$ value \\
\hline \multicolumn{5}{|l|}{ Age (years) } \\
\hline$\leq 59$ & 18 & 8 & 10 & $\mathrm{~N}$ \\
\hline$>59$ & 22 & 7 & 15 & \\
\hline \multicolumn{5}{|l|}{ Gender } \\
\hline Male & 25 & 10 & 15 & \multirow{2}{*}{$\mathrm{N}$} \\
\hline Female & 15 & 5 & 10 & \\
\hline \multicolumn{5}{|l|}{ Bormann Type } \\
\hline I, II & 14 & 5 & 9 & $\mathrm{~N}$ \\
\hline III, IV & 26 & 10 & 16 & \\
\hline \multicolumn{5}{|l|}{ Location } \\
\hline Middle Proximal & 17 & 6 & 11 & $\mathrm{~N}$ \\
\hline Distal & 23 & 9 & 14 & \\
\hline \multicolumn{5}{|l|}{ Diameter $(\mathrm{cm})$} \\
\hline$\leq 5$ & 22 & 8 & 14 & $\mathrm{~N}$ \\
\hline$>5$ & 18 & 7 & 11 & \\
\hline \multicolumn{5}{|l|}{ Histologic type } \\
\hline Intestinal & 12 & 4 & 8 & $\mathrm{~N}$ \\
\hline Diffuse & 28 & 11 & 17 & \\
\hline \multicolumn{5}{|l|}{ Depth of invasion } \\
\hline $\mathrm{T} 1, \mathrm{~T} 2$ & 11 & 4 & 7 & $\mathrm{~N}$ \\
\hline T3, T4 & 29 & 11 & 18 & \\
\hline \multicolumn{5}{|l|}{ Lymph node metastasis } \\
\hline No & 15 & 2 & 13 & 0.020 \\
\hline Yes & 25 & 13 & 12 & \\
\hline \multicolumn{5}{|l|}{ Differentiation } \\
\hline High, Middle & 14 & 5 & 9 & $\mathrm{~N}$ \\
\hline Moderate, Low & 26 & 10 & 16 & \\
\hline \multicolumn{5}{|l|}{ TNM stage } \\
\hline I, II & 13 & 1 & 12 & 0.013 \\
\hline III, IV & 27 & 14 & 13 & \\
\hline \multicolumn{5}{|l|}{ P-AKT expression } \\
\hline Positive & 23 & 12 & 11 & 0.046 \\
\hline Negative & 17 & 3 & 14 & \\
\hline \multicolumn{5}{|l|}{ MMP9 expression } \\
\hline Positive & 19 & 11 & 8 & 0.021 \\
\hline Negative & 21 & 4 & 17 & \\
\hline
\end{tabular}

Abbreviation: $\mathrm{N}$, no significant difference between groups.

The AR expression level associated with clinicopathological features, including tumor size, lymph node metastasis, local invasion, and tumor-node-metastasis (TNM) stage are shown. Statistical significance was assessed by Pearson $\chi 2$ test. 
There was no significant difference between male and female patients in terms of AR expression (positive rate: $10 / 25$ vs $5 / 15$, Table 1 ). Interestingly, we found a significant difference in the AR positive rate between GC with or without lymph node metastasis $(13 / 25$ vs $2 / 15$, Table 1), which has not been described previously. Similarly, we found that the average expression level of AR was significantly upregulated in tumor tissues of patients with later TNM stages (III and V) compared with that in patients with earlier TNM stages (I and II) (14/27 vs $1 / 13$, Table 1$)$. It has also been reported that MMP2 and MMP9 are involved in GC metastasis via the AKT signaling pathway [23]. Therefore, we detected MMP2/ MMP9 and P-AKT expression in the corresponding GC tissues using IHC to explore the correlation of AR and some key molecules involved in GC cell migration and invasion. As shown in Table 1 and Fig. 1a, AR expression was positively correlated with the expression of P-AKT and MMP9 but not MMP2. Next, we evaluated the protein expression of AR, P-AKT, MMP2, and MMP9 in the corresponding tissues to validate the results of IHC (Fig. 1b). Collectively, the results provided strong evidence that AR might play a prominent role in gastric carcinogenesis.

\section{Overexpression of AR promotes GC cell migration, invasion and proliferation in vitro}

To elucidate the effect of AR on the malignant phenotypes of GC cells, WB was used to examine the endogenous AR expression of 7 adherent parental gastric cell lines. Our data showed that AR expression level in SGC-7901 cells was lower than CRL-5822 but higher than other cell lines (Fig. 2a), which allowed us to upregulate or downregulate AR conveniently, so we selected it as our tool cell in the following experiments. we assessed the effects of AR overexpression on cell migration, invasion and proliferation, which are key determinants of GC cells. As shown in Fig. 2b, compared with the control, ectopic expression of AR led to significant increases in the migration and invasion of GC cells. The AR overexpression group also showed faster motility in a wound healing assay $(\mathrm{P}<0.05)$ (Fig. 2c). Additionally, cells in the AR overexpression group grew more rapidly (Fig. $2 \mathrm{~d})$. Taken together, these results indicate a functional role for $\mathrm{AR}$ in mediating cell migration, invasion, and proliferation in GC.

\section{AR upregulates MMP9, which depends on the phosphorylation of AKT in vitro}

As shown in Fig. 1 and Table 1, AR overexpression was accompanied by an increase in the activation of AKT and upregulation of MMP9, which suggests a potential signaling pathway that mediates the effects of AR on gastric carcinogenesis. Molecules involved in the
AKT pathway were measured by WB to investigate their distribution. Compared with the control group, we found that the protein expression level of MMP9, but not MMP2, was markedly increased in the AR+ group. In contrast, MMP9 but not P-AKT expression was sharply decreased by AR siRNA (Fig. 3a), which indicate that MMP9 may be

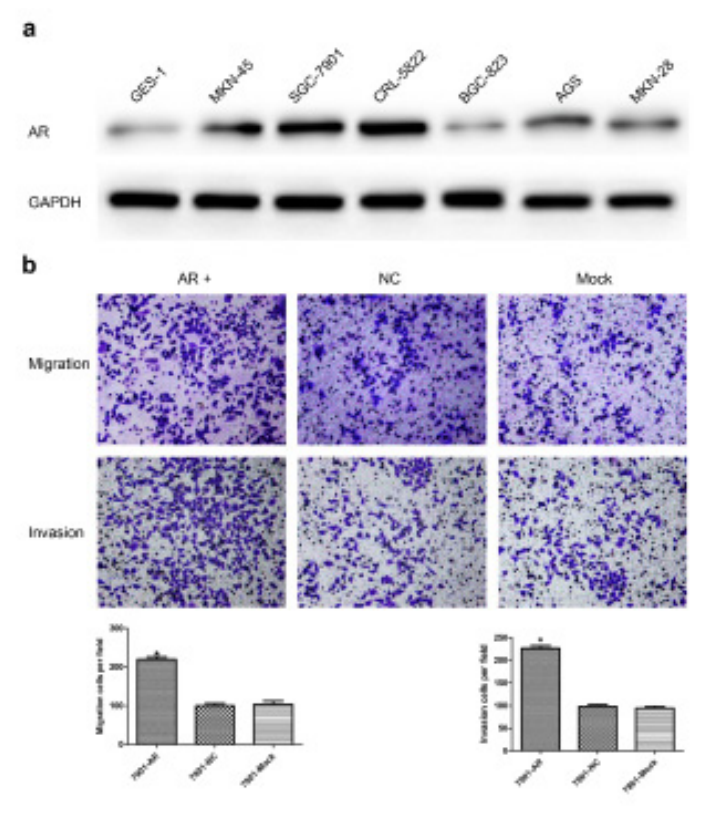

c
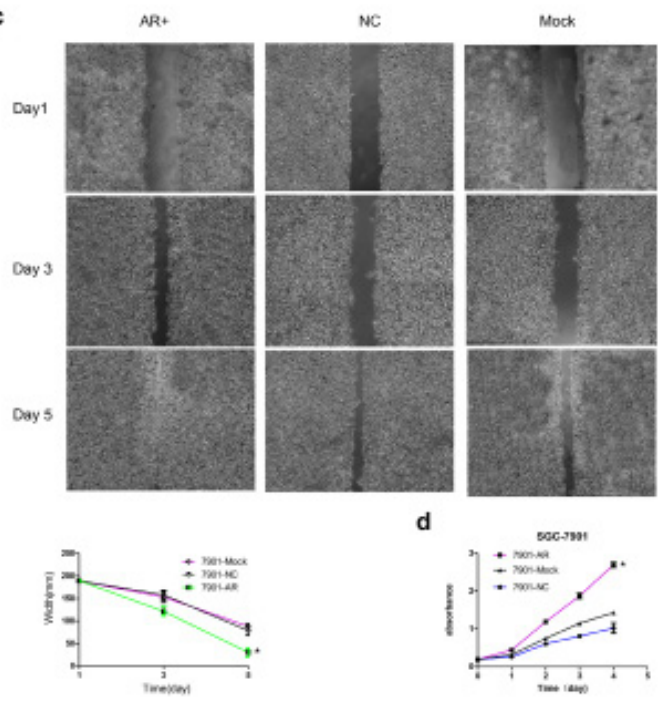

d

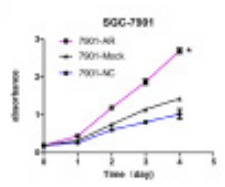

Fig.2: Effects of AR overexpression on the migration, invasion, and proliferation of SGC-7901 cells. (a) Endogenous expression of AR in seven adherent parental GC cell lines. AR expression level in SGC-7901 cells was lower than CRL-5822 but higher than other cell lines. (b) AR promoted the migration and invasion of SGC-7901 cells in vitro. Up: Representative photographs of transwell assays. Low: Histograms showed the cell numbers per field of migration (Left) and invasion (Right). (c) Up: Representative photographs of wound healing assays. Low: wound healing curve. AR promoted the wound healing rate of SGC-7901 cells in vitro. (d) Cell proliferation curve measured by a Cell Counting Kit- 8 assay. Results are the mean of three independent experiments \pm $\mathrm{SD}(* \mathrm{P}<0.05)$ (original magnification, $\times 200)$. 
in the downstream of the AR. Besides, Compared with the control, when the activity of AKT was blocked by siRNA or the inhibitor, a remarkably decrease in AR expression

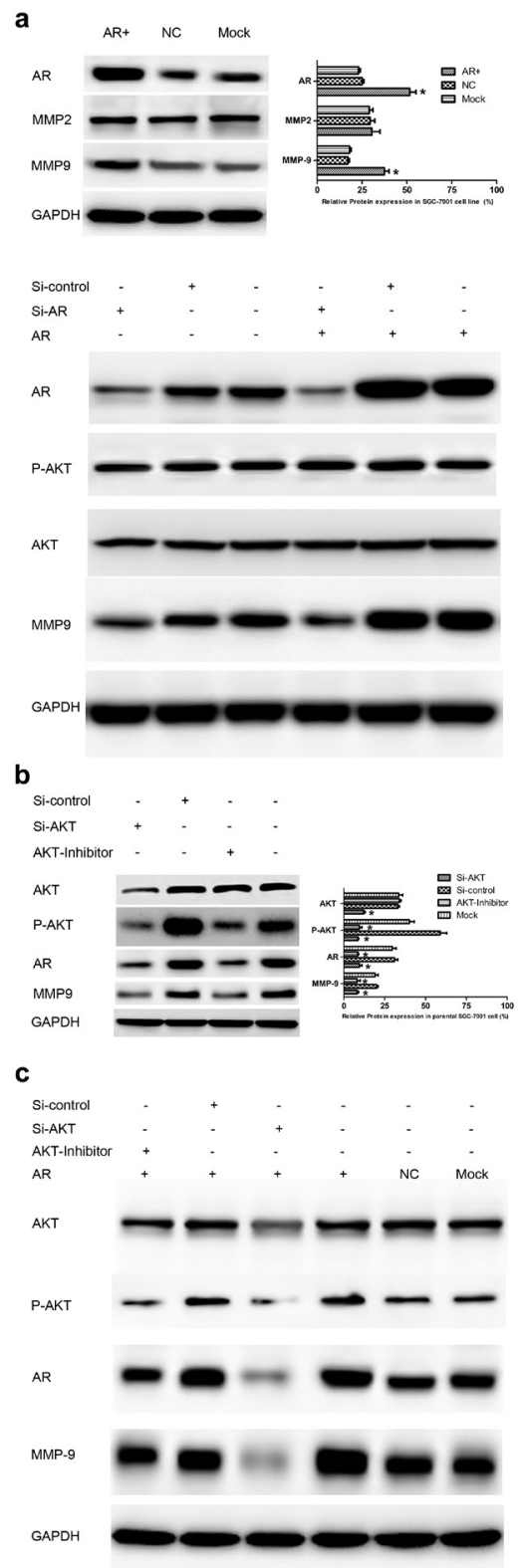

Fig.3: AR upregulates MMP9, which depends on the phosphorylation of AKT in vitro. (a) Up: AR overexpression upregulated MMP9 (Left). Bar charts represented relative expression of different proteins (Right). Low: AR knockdown by siRNA or inhibitor decreased MMP9 expression. (b) Influence of AKT activity inhibition on endogenous expression of AR. The AR protein level was decreased significantly by siRNA or the inhibitor of AKT, which was accompanied by a decrease in MMP9 expression (Left). Bar charts represented relative expression of different proteins (Right). (c) Effect of AKT inhibition on AR protein expression in stably transfected SGC-7901 cells. AR protein expression was significantly downregulated by inhibition of AKT, which was accompanied by a decrease in MMP9 expression. Results are the mean of three independent experiments $\pm \mathrm{SD}(* \mathrm{P}<0.05)$. appeared along with downregulation of MMP9, however, AKT/P-AKT expression was not changed by AR (Fig. $3 \mathrm{~b}$ and Fig. 3c). Taken together, these data demonstrate

a

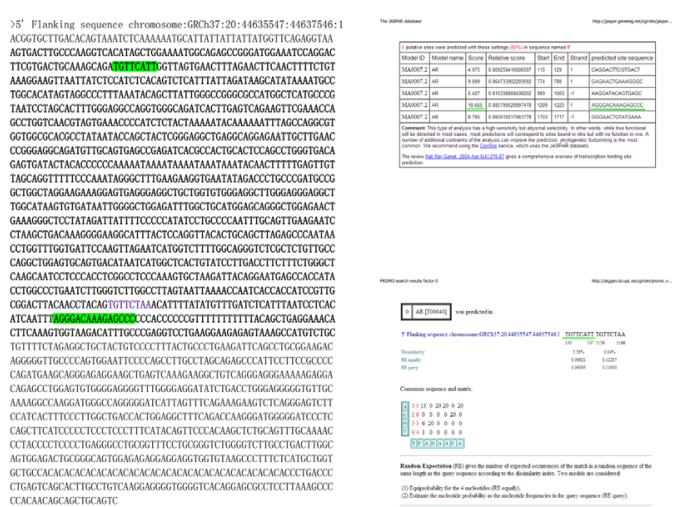

b

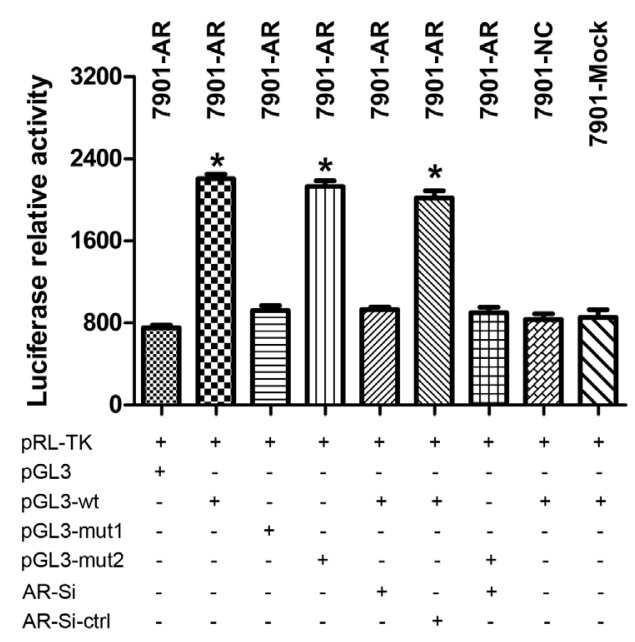

C

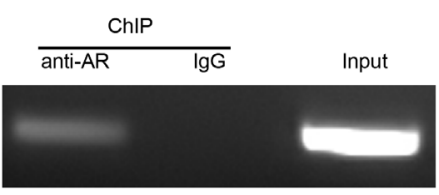

Fig.4: AR enhances MMP9 expression by binding to its promoter region in SGC-7901 cells. (a) MMP9 promoter region and AR-binding sites predicated by two different on-line tools. Bold on the left indicated the amplified portion of the promoter region, and bold on the right (Up and Low) indicated the binding sites with high scores. (b) Luciferase report assays. A reporter plasmid for MMP9 (pGL3-MMP9) was generated by cloning the MMP9 promoter region (wt) or its mutants (mut1 and mut2) into the pGL3-basic vector. AR significantly increased the luciferase activity of MMP9 promoter region, which was significantly reduced by knockdown of AR. Mut1 may contained the AR-binding site. (c) MMP9 promoter region and AR interaction validated by ChIP assays. MMP9 cDNA was detectable in the immunoprecipitated chromatin samples of SGC7901-AR cells using an antibody against AR, suggesting that AR binds to the MMP9 promoter. Genomic DNA and IgG were used as controls. Results are the mean of three independent experiments $\pm \mathrm{SD}(* \mathrm{P}<0.05)$. 
that AR upregulates MMP9, which depends on the phosphorylation of AKT.

\section{AR enhances MMP9 expression by binding to its promoter region}

As a key transcription factor, AR plays an important role in many pathophysiology processes, including carcinogenesis. To investigate the precise mechanism by which AR promotes the malignant phenotypes of GC, luciferase and chromatin immunoprecipitation (ChIP) assays were performed. We analyzed the MMP9 promoter region for potential AR-binding sites using online tools (http://alggen.lsi.upc.es/cgi-bin/promo_v3/promo/ promoinit.cgi?dirDB $=\mathrm{TF} 8.3$ and http://jaspar.genereg. net/), and found two putative sites with high scores ( -139 to $-148 \mathrm{nt}$ and -1208 to $-1223 \mathrm{nt}$ ) (Fig. 4a). Then, firefly luciferase reporter plasmids containing the MMP9 promoter with the potential AR-binding sites (MMP9WT/MT1/MT2) were constructed. Our data showed that the luciferase activity was higher in SGC-7901/AR cells co-transfected with MMP9-WT or MMP9-MT2 than that in control cells. However, the activity was significantly decreased when the cells were transfected with ARsiRNA. Moreover, we found no difference in the luciferase activity between MMP9-MT1 and control groups, which indicate that MT1 might contain the AR-binding site (Fig. $4 \mathrm{~b})$. Then the luciferase assay results were validated by ChIP assays (Fig. 4c). Taken together, these data suggest that AR upregulates MMP9 by binding to its promoter.

\section{AR-mediated enhancement of migration, invasion and proliferation can be reversed by inhibition of AR, AKT or MMP9}

To examine the effect of AR downregulation on $\mathrm{GC}$ cell migration, invasion, and proliferation, we first assessed the effects of AR, AKT and MMP9 inhibition by siRNA or inhibitors on cell motility in wound healing assays. As shown in Fig. 5a, cell motility was decreased significantly after their inhibition, which reversed the differences shown in Fig. $2(\mathrm{P}<0.05)$. Next, to investigate whether the growth-prompting effect could be reversed by AR or AKT inhibition, AR or AKT was blocked in AR-overexpressing cells followed by analysis of cell proliferation. As a result, the enhancement of proliferation induced by AR was reduced sharply $(\mathrm{P}<0.05)$ (Fig. $5 b)$. Then, the migration and invasion of AR-overexpressing cells was assessed after inhibition of AR or AKT or MMP9. As shown in Fig. 5c and Fig. 5d, the data indicated a sharp reversal in the promoting effect of AR on the migration and invasion of SGC-7901 cells $(\mathrm{P}<0.05)$. Taken together, these results confirm the functional role of AR in mediating cell migration, invasion and proliferation in GC.

\section{Overexpression of $A R$ promotes tumor growth and metastasis in vivo}

We examined whether overexpression of AR could promote tumor growth and peritoneal metastasis in vivo. SGC-7901/AR or control cells were injected subcutaneously or peritonealy into nude mice, and subcutaneous tumor formation was monitored by growth curves (Fig. 6a) $(\mathrm{P}<0.05)$. After 35 days, the mice were

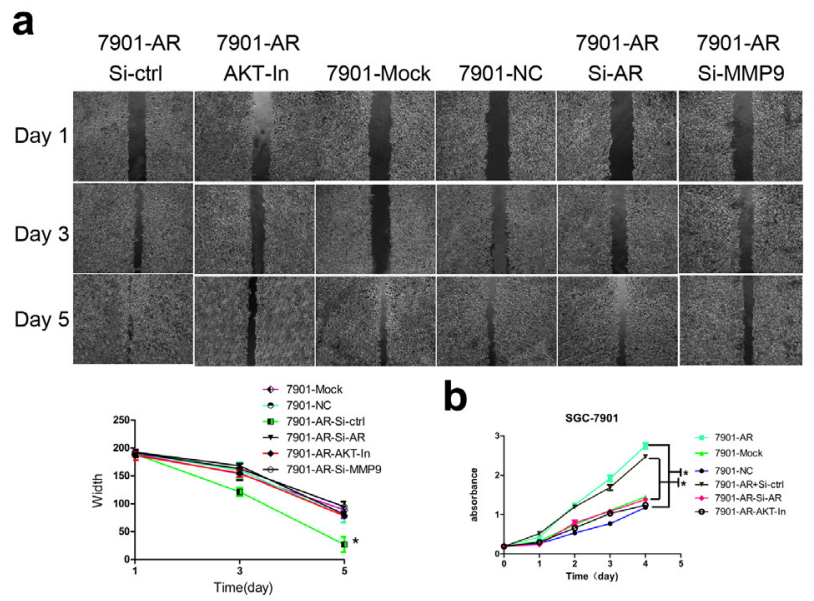

C
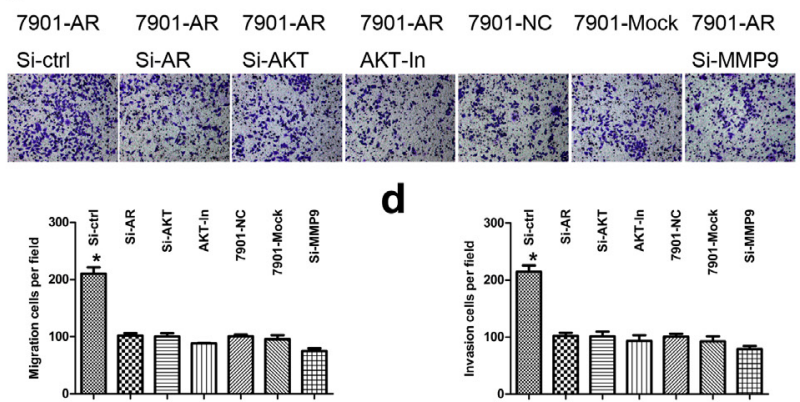

d
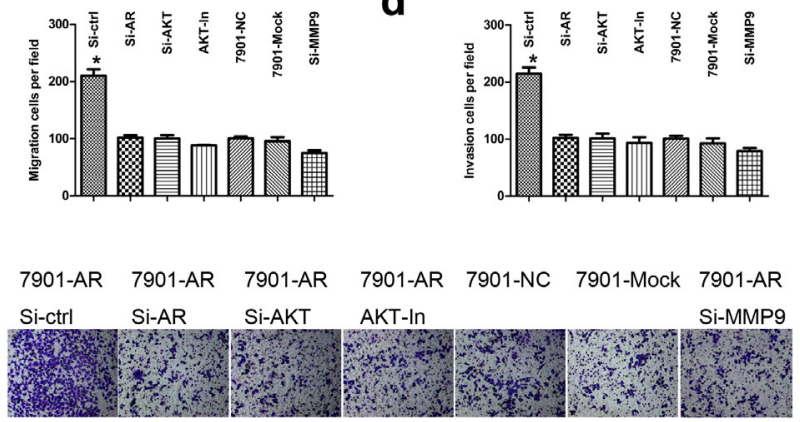

Fig.5: Effect of AR inhibition on the migration, invasion and proliferation of SGC-7901 cells. (a) Enhanced motility of AR-overexpressing cells in the wound healing assay was reversed by inhibition of AR, AKT or MMP9 (Up). Wound healing curve (Low). (b) CCK8 cell proliferation curve. Enhancement of AR-overexpressing cell proliferation was inhibited by suppression of AR or AKT. (c) Transwell assays. The migration-promoting effect induced by AR upregulation was prevented by downregulation of AR or MMP9 or inhibition of AKT in vitro (Up). Histograms showed the cell numbers per field of migration (Low). (d) Histograms showed the cell numbers per field of invasion (Up). The invasion-promoting effect induced by AR upregulation was prevented by downregulation of AR, MMP9 or inhibition of AKT in vitro (Low). Results are the mean of three independent experiments $\pm \mathrm{SD}(* \mathrm{P}<0.05)$ (original magnification, $\times 200$ ). 
euthanized and subcutaneous tumor weights or peritoneal tumor numbers were assessed. Data indicated that tumors grew slower in the control group than that in the SGC7901/AR group (Fig. 6a). The average weight of tumors from SGC-7901/AR cells was significantly larger than that of tumors from control cells $(2200 \pm 190 \mathrm{mg}$ vs. $870 \pm$ $570 \mathrm{mg})(\mathrm{P}<0.05)$. Additionally, as shown in Fig. $6 \mathrm{~b}$, the number of tumors of peritoneal metastases in the SGC$7901 /$ AR group was significantly larger than that in the control group $(\mathrm{P}<0.05)$.

Besides, IHC analysis of Ki-67 antigen revealed that the increased tumor growth in mice was in part owing to more rapid proliferation caused by AR overexpression. The number of Ki-67 antigen-positive cells was higher in tumors derived from SGC-7901/AR cells than that in tumors derived from control cells $(\mathrm{P}<0.05)$ (Fig. 6c). To assess whether the correlation between AR and P-AKT or MMP9 could be recapitulated in vivo, $\mathrm{P}-\mathrm{AKT}, \mathrm{AR}$, and MMP9 were detected by IHC (Fig. 6c). The data were consistent with the results in Fig. 1. Next, WB was applied to confirm the results of IHC (Fig. 6d). These data suggest that the promoting effect on tumorigenicity of $\mathrm{AR}$ is attributed to increased proliferation and enhanced metastasis in vivo.

\section{DISCUSSION}

AR expression has been documented in liver, colon and brain tumors [24-26]. In GC, AR expression has been reported [7] but the precise mechanism by which AR is involved in gastric carcinogenesis has not been explored. Besides, in most studies, it was found to be insignificant or conflicting. Gan et al revealed that AR is expressed independently and shows a decrease in its expression in GC compared with that in adjacent normal tissues [27]. But in a recent study, it was reported that AR-negative patients have significantly better survival than AR-positive

Fig.6: Overexpression of AR promotes tumor growth and migration in vivo. (a) Photographs of tumors derived from SGC7901/AR and control SGC-7901 cells injected subcutaneously into nude mice. Growth kinetics curve of tumors in nude mice (Low left). Tumor diameters were measured every 7 days. Average tumor weights in nude mice (Low right). AR/ Ki-67, mainly located in nucleus, AKT/P-AKT/MMPs mainly located in cytoplasm and nucleus. (b) Photographs of tumors derived from SGC7901/AR and control SGC-7901 cells injected peritonealy into nude mice. The general condition of mice (Up left). Bar charts showed numbers of tumors formed in the peritoneal cavity (Up right). Representative photographs of tumors formed in the peritoneal cavity (Low). (c) Representative IHC photographs of Ki-67 antigen, P-AKT, AR and MMP9 in tumors of nude mice. (d) Representative WB pictures of P-AKT, AR and MMP9 in tumors of nude mice (Left). Bar charts indicated relative expression levels of different proteins (Right). Results are the mean of three independent experiments \pm SD $(* \mathrm{P}$ $<0.05$ ) (original magnification, $\times 200$ ). patients [11]. The authors' results are in accordance with the reported data that showed AR immunopositivity was observed in 15 out of 40 gastric tumors and its

a
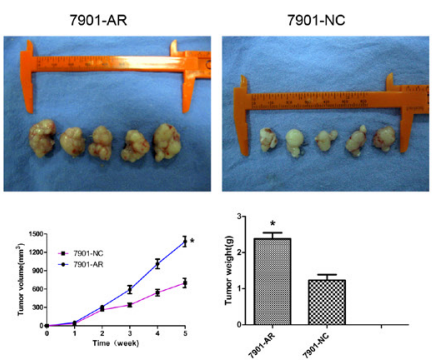

b
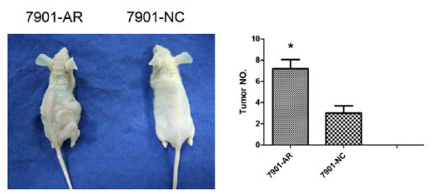

7901-AR

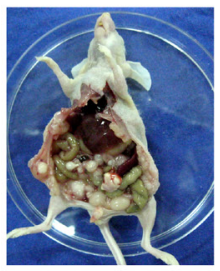

7901-NC

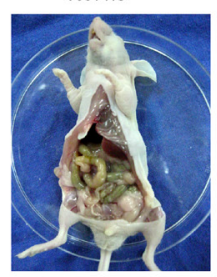

C

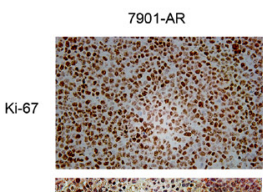
7901-NC

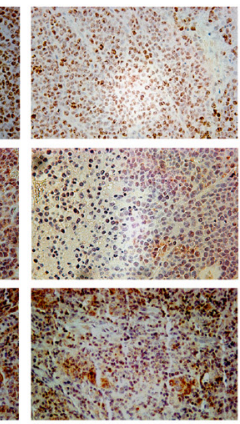

AKT
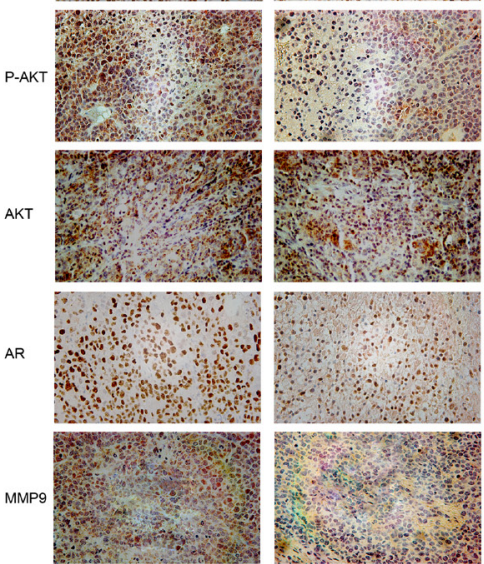

d

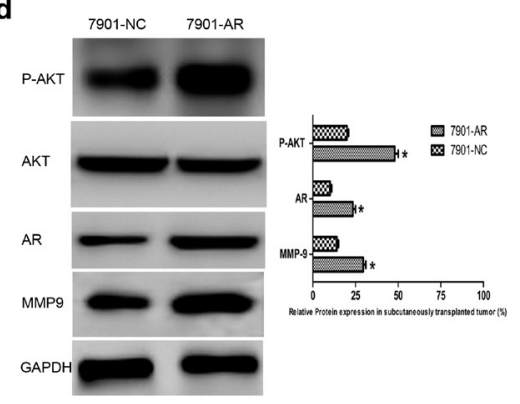


overexpression was positively correlated with lymph node metastasis and late TNM stages. The antibodies employed, sample size, and positive criteria may account for the differences between studies.

The present study revealed that there was no difference in the AR expression of tumors in male and female subjects. This result reflects the fact that activation of the AR pathway can be either ligand dependent or mediated by ligand-independent mechanisms. Castrationresistant prostate cancer may develop as a consequence of the dysregulated AR signaling that results from AR amplifications, altered interactions of co-regulatory molecules during transcription as well as non-steroidal activation by growth factors, cytokines, and neurosecretory products [28].

Considering the male predominance of GC and the lack of information available on AR expression in the stomach, detailed mechanistic studies need to be conducted to reveal the mechanism of AR functions in normal stomach and GC. Accumulated evidences implicate AR was involved in the process of carcinogenesis. AR promotes prostate cancer progression by direct suppression of the tumor suppressor gene $\mathrm{CCN} 3 / \mathrm{NOV}$, and it enhances ligand-independent prostate cancer progression through c-Myc upregulation [29, 30].The aforementioned ARregulated genes underscore the significance of aberrant AR activity in the development and progression of neoplasia. If we can confirm the role of AR as an important regulator in GC tumorigenicity, AR may serve as a novel prognostic cancer marker and a new target of GC therapeutics.

We demonstrated that AR overexpression promoted GC cell migration, invasion and proliferation, and our results were confirmed by in vivo experiments. Recent in vitro studies focusing on the molecular interactions of hormone receptors with oncoproteins have been confirmed $\mathrm{s}$ in animal models [31, 32]. However, the signaling pathway involved in the AR signal in $\mathrm{GC}$ has not been reported. Wang et al indicated that AR can directly interact with PI3 kinase to ultimately upregulate AKT phosphorylation [33]. However, the data are conflicting. Lin et al demonstrated that AR phosphorylation by AKT results in MDM2-mediated ubiquitylation of AR, leading to its proteasomal degradation [34]. These data indicate that the regulation effect of AKT and AR on each other may dependent on the microenviroenment they're involved in, including different co-regulators [35].

Our results indicated that an increase in AKT activity correlated with increased AR protein expression. To confirm this, we assessed the effect of AKT inhibition on GC cells and data showed that AKT suppression resulted in downregulation of $\mathrm{AR}$ protein expression and decreases in GC cell migration, invasion, and proliferation. This is the first report to demonstrate that AR induces GC cell migration and invasion via activation of AKT. However, the exact mechanisms by which AR signaling enhanced gastric carcinogenesis remain largely unknown. One potential target by which AR increases the invasion and migration of cancer cells is MMPs. It is well established that secretion of MMPs with the capacity for ECM degradation is a feature of metastatic cancer cells [36]. MMP2 and MMP9 are most wellcharacterized MMPs with strong proteolytic activity in the ECM [37]. We found that MMP9, but not MMP2, was a key molecule that mediated AKT/AR signals to enhance the metastatic potential of GC, which may be due to different co-regulators that interact with $\mathrm{AR}$ in various microenvironments [35]. We also found that the AR-induced upregulation of MMP9 was promoter dependent and these effects were attenuated or inhibited by AR siRNA. Some recent studies have shown that AR upregulates MMP9 expression and activity in prostate cancers [38, 39]. These observations, together with our current findings, may allow us to develop a new therapeutic approach based on targeting these molecules to block GC metastasis.

In summary, we have shown for the first time that $\mathrm{AR}$ is functionally involved in the regulation of metastasis in GC. This molecular mechanism involves AR-mediated up-regulation of MMP9 via activation of AKT. Our study strongly suggests that the P-AKT/AR/MMP9 pathway may be a potential target for therapeutic strategies to enhance the survival of GC patients.

\section{METHODS}

\section{Tissues and cell lines}

Tissues were resected for GC treatment at Ruijin Hospital, Shanghai Jiao Tong University School of Medicine (Shanghai, China) between 2012 and 2014. Sections were prepared from $10 \%$ formalin-fixed, paraffinembedded GC tissues. All cases of GC were histologically diagnosed according to the Japanese Classification of Gastric Carcinoma and Lauren's classification [40, 41]. Human GC cell lines, SGC-7901, MKN-28, MKN-45, and AGS were purchased from the Shanghai Institutes for Biological Sciences, Chinese Academy of Sciences, and BGC-823 and CRL-5822 GC cell lines were purchased from the American Type Culture Collection (ATCC). The immortalized normal gastric mucosal epithelial cell line GES-1 was a kind gift from Prof. Feng Bin (Sichuan University, Chengdu, China). The cells were cultured routinely in RPMI-1640 supplemented with 10\% heatinactivated fetal bovine serum (FBS), 100U/ml penicillin and $100 \mu \mathrm{g} / \mathrm{ml}$ streptomycin in a humidified cell incubator with $5 \% \mathrm{CO}_{2}$ at $37^{\circ} \mathrm{C}$. Exponentially growing cells were used for experiments. 


\section{IHC and WB}

For IHC, all staining steps were performed at room temperature and the samples were washed with PBS between steps. Sections were de-waxed before incubation with primary antibodies (rabbit anti-P-AKT/AR/MMP2/ MMP9) (Abcam, Cambridge, UK) for $1 \mathrm{~h}$. A biotinylated swine anti-rabbit (Dako, Glostrup, Denmark) secondary antibody was applied for an additional hour following the removal of primary antibodies. Staining was developed with an avidin-biotinylated horseradish peroxidase complex (Dako) and 3, 3'-diaminobenzidine (Dako) following the manufacturer's instructions. Expression of P-AKT/AR/MMP2/MMP9 was detected in the cytoplasm, nuclei or intercellular areas. Positivity of more than $15 \%$ of the carcinoma cells was considered as overexpression of the proteins. For WB, tissue samples were lysed using T-PER Tissue Protein Extraction Reagent (Pierce) in the presence of a protease inhibitor cocktail (Pierce). For cultured cells, trypsinized cells were washed with PBS and then subjected to sonication in $50 \mathrm{mM}$ Tris- $\mathrm{HCl}$ buffer (pH 8.0) containing $1 \%$ glycerol, $1 \mathrm{mM}$ EDTA, $0.5 \mathrm{mM}$ PMSF, and $2 \mathrm{mM}$ benzamidine followed by centrifugation. Equal amounts of protein $(100 \mu \mathrm{g})$ were electrophoresed on $12 \%$ reducing SDS-polyacrylamide gels. The proteins were electrotransferred to Immobilon-P membranes. The membranes were blocked with 5\% non-fat dry milk in Tris-buffered saline (TBS; pH 8.0) containing 0.1\% Tween-20 for $2 \mathrm{~h}$, and subsequently incubated with rabbit antibodies at $1 \mu \mathrm{g} / \mathrm{ml}$. Antigen-antibody complexes were visualized using enhanced chemiluminescence. In most cases, blots were re-probed with an antibody against glyceraldehyde-3-phosphate dehydrogenase to assess protein loading. Band intensities were quantitated using a Tanon 2500 imaging system (TANON).

\section{Establishment of stable transfectants}

Wild-type AR (WT-AR) in a pcDNA3.1 (+) plasmid was kindly provided by Dr. Masahiro Takeyoshi (Research Section I, Chemicals Assessment and Research Center, Chemicals Evaluation and Research Institute, Japan) and Prof. Li-Chun Xu (Xuzhou Medical College). The pcDNA3.1 (+) mammalian expression vector was purchased from NOVOBIO. GC cells were plated at a density of $2 \times 10^{5} \mathrm{cells} / \mathrm{cm}^{2}$, cultured for 24 $\mathrm{h}$, and then transfected with vectors using $4 \mu \mathrm{g}$ DNA and Lipofectamine (Invitrogen). After 24h, every $48 \mathrm{~h}$ thereafter for 4 weeks, the culture medium was replaced with fresh medium containing $800 \mu \mathrm{g} / \mathrm{ml} \mathrm{G} 418$. Pools of 16 clones were isolated as stable transfectants with an AR expression vector or an empty vector.
Transfection of siRNA and plasmids and inhibitor treatments

SiRNA used in our study mainly target the gene coding regions, which allowed it to knockdown both the endogenous and exogenous AR protein expression effectively and efficiently. 750pmol scrambled siRNA oligos or SiRNAs that specifically targeted human AKT, AR, or MMP9 (Santa Cruz, CA, USA) were transfected into GC cells $\left(2 \times 10^{6}\right)$ using a Lip2000 transfection reagent kit according to the manufacturer's instructions. For plasmid transfections, plasmid DNA and Lipofectamine were diluted separately in serum-free medium and then incubated at room temperature for $5 \mathrm{~min}$. The diluted DNA and Lipofectamine were then mixed and incubated at room temperature for $20 \mathrm{~min}$. Aliquots of the transfection mixture were then added to the cells. For inhibitor treatments, we used an AKT Inhibitor (MK-2206 $2 \mathrm{HC}$ ) (Selleck) at $15 \mathrm{nM}$.

\section{Wound healing assays}

GC cells were cultured to $100 \%$ confluence in sixwell plates. Wound healing assays were performed by scratching the cell monolayer with a sterile $20-\mu \mathrm{L}$ pipette tip. The cells were then washed once with PBS. Migration of the cells was evaluated at days 1,3 and 5 under an inverted phase-contrast microscope (Olympus).

\section{Cell proliferation assays}

At $24 \mathrm{~h}$ post-transfection, cells $\left(2 \times 10^{3}\right.$ cells/well $)$ were seeded into 96-well plates and incubated for 5 days. Cell proliferation was assessed by a water-soluble tetrazolium salt assay using Cell Counting Kit-8 (Dojindo, Kumamoto, Japan) according to the manufacturer's instructions. All experiments were performed in triplicate.

\section{Cell invasion and migration assays}

We employed the Boyden chamber technique (transwell analysis). Briefly, $8 \mu \mathrm{m}$ pore size filters were coated with $100 \mu \mathrm{l}$ of $1 \mathrm{mg} / \mathrm{ml}$ matrigel (dissolved in serum-free RPMI-1640) (migration assays omit matrigel). A total of $600 \mu 1$ RPMI-1640 containing $10 \%$ FBS was added to the lower chambers. Single cell suspensions (1 $\times 10^{5}$ cells/well) were added to the upper chambers and allowed to invade for $24 \mathrm{~h}$ at $37^{\circ} \mathrm{C}$ in a $\mathrm{CO}_{2}$ incubator. Cells remaining attached to the upper surface of the filters were carefully removed with cotton swabs. Invaded cells were stained with $0.1 \%$ crystal violet for $10 \mathrm{~min}$ at room temperature and examined by light microscopy. 


\section{Luciferase reporter assay}

The human MMP9 gene promoter was amplified by PCR and cloned into the multi-cloning site of a pGL3 reporter plasmid (Ambion) containing the WT firefly luciferase reporter gene. To introduce mutations into the seed sequences of the two AR-binding sites in the promoter and generate MMP9 MT1 and MT2 reporters, plasmids were constructed by overlap extension PCR. Cells seeded into 24-well plates were co-transfected with different plasmids (firefly reporter constructs containing the MMP9 promoter, a Renilla-expressing plasmid, pRL-TK, AR plasmid or control plasmid). Firefly and Renilla luciferase activities were measured at $24 \mathrm{~h}$ posttransfection by the Dual Luciferase Assay System (Promega). Firefly luciferase activity was normalized to Renilla luciferase activity.

\section{ChIP assay}

To evaluate the interaction between $\mathrm{AR}$ and MMP9 promoter region, ChIP assays were performed using a kit (Millipore) according to the manufacturer's instructions. Cells were fixed with formaldehyde for protein/DNA crosslinking and then lysed. The DNA was sheared by sonication (15 pulses, $35 \mathrm{~s}$ on $35 \mathrm{~s}$ off) and then added to a well coated with an anti-AR antibody. Washes were performed to remove unbound material, and then AR-bound DNA was released by protein digestion with proteinase $\mathrm{K}$. The DNA was purified through a column. PCR was performed using primers designed to target the MMP9 promoter region spanning the site of the interaction with AR. Primers were as follows: MMP9-F: GCAAAGTGTTCATTG GTTAGTGAACTTTAGAACTTCAA; MMP9-R: TTTTTTGCCCCCCACCCCCCGAGAAACAGGGAT TTAAC. Genomic DNA and IgG were used as controls.

\section{In vivo experiments}

Stably transfected cells with the AR or control plasmid $\left(1 \times 10^{6}\right.$ or $2 \times 10^{6}$ in $\left.150 \mu \mathrm{L}\right)$ were injected subcutaneously or into the peritoneal cavity of 4-week-old male nude mice (Institute of Zoology, Chinese Academy of Sciences, Shanghai, China). Mice were checked weekly, and tumor nodules were measured with a caliper. Tumor volumes were evaluated using the following formula: volume $=($ width + length $) / 2 \times$ width $\times$ length $\times 0.5236$. Mice were sacrificed after 5 weeks. Tumor growth curves and promotion rates were calculated. All tumors were excised, weighed, harvested and embedded in paraffin. A mouse anti-human Ki-67 antigen monoclonal antibody (Dako, 1:50 dilution) was used to determine nuclear expression of Ki-67 by IHC.

\section{Ethics statement}

All animal experiments were conducted according to the Chinese guidelines for animal experimentation and approved by the Institutional Animal Care Committee of Shanghai Jiao-Tong University School of Medicine, Ruijin Hospital. All patients provided written informed consent before enrollment, and the Ethics Committee of Shanghai Jiao-Tong University School of Medicine, Ruijin Hospital approved the study protocol. The study was carried out according to the provisions of the Helsinki Declaration of 1975.

\section{Statistical methods}

Statistical analyses were performed with SPSS Version 19.0 using the Student's t-test or one-way analysis of variance, chi-squared test, Fisher's exact test or MannWhitney U-test. Differences were considered statistically significant in two-tailed tests with $\mathrm{p}$-values of $<0.05$.

\section{Disclosure of potential conflicts of interest}

There no potential conflicts of interest to declare.

\section{ACKNOWLEDGEMENTS}

This study was supported by grants from the National Natural Science Foundation of China (No. 81172324, No. 91229106, No. 81272749, and No. 81372231), Science and Technology Commission of Shanghai Municipality (No. 13ZR1425600), Key Projects in the National Science \& Technology Pillar Program of China (No. 2014BAI09B03), and the Key Project of Shanghai Education Committee (No. 12ZZ105 andNo.12ZZ102)

\section{REFERENCES}

1. Negi SS, Agarwal A and Chaudhary A. Flutamide in unresectable pancreatic adenocarcinoma: a randomized, double-blind, placebo-controlled trial. Invest New Drugs. 2006; 24(3):189-194.

2. Chen PJ, Yeh SH, Liu WH, Lin CC, Huang HC, Chen CL, Chen DS and Chen PJ. Androgen pathway stimulates MicroRNA-216a transcription to suppress the tumor suppressor in lung cancer-1 gene in early hepatocarcinogenesis. Hepatology. 2012; 56(2):632-643.

3. Catalano V, Labianca R, Beretta GD, Gatta G, de Braud F and Van Cutsem E. Gastric cancer. Crit Rev Oncol Hematol. 2009; 71(2):127-164.

4. Ma WL, Hsu CL, Wu MH, Wu CT, Wu CC, Lai JJ, Jou YS, Chen CW, Yeh S and Chang C. Androgen receptor is a new potential therapeutic target for the treatment 
of hepatocellular carcinoma. Gastroenterology. 2008; 135(3):947-955, 955.e941-945.

5. Feng H, Cheng ASL, Tsang DP, Li MS, Go MY, Cheung YS, Zhao GJ, Ng SS, Lin MC, Yu J, Lai PB, To KF and Sung JJY. Cell cycle-related kinase is a direct androgen receptor-regulated gene that drives beta-catenin/T cell factor-dependent hepatocarcinogenesis. J Clin Invest. 2011; 121(8):3159-3175.

6. Yeh SH and Chen PJ. Gender Disparity of Hepatocellular Carcinoma: The Roles of Sex Hormones. Oncology. 2010; 78:172-179.

7. $\mathrm{Wu} \mathrm{CW}$, Chi CW, Chang TJ, Lui WY and P'Eng F K. Sex hormone receptors in gastric cancer. Cancer. 1990; 65(6):1396-1400.

8. Iushkov PV. [Sex hormone receptors in the gastric mucosa in gastric precancer and cancer]. Arkh Patol. 1997; 59(3):24-27.

9. Polimeno L, Silecchia G, Spaziani E, Scucchi A, Dell'Aquila P, Ierardi E, Materia A, Giangaspero A, Basso $\mathrm{N}$ and Francavilla A. Estrogens, androgens, and EGF receptor expression in gastric carcinoma induced by N-methyl-N'-nitro-N-nitrosoguanidine. Dig Dis Sci. 1994; 39(3):635-640.

10. Matsui M, Kojima O, Kawakami S, Uehara Y and Takahashi T. The prognosis of patients with gastric cancer possessing sex hormone receptors. Surg Today. 1992; 22(5):421-425.

11. Kominea A, Konstantinopoulos PA, Kapranos N, Vandoros G, Gkermpesi M, Andricopoulos P, Artelaris S, Savva S, Varakis I, Sotiropoulou-Bonikou G and Papavassiliou AG. Androgen receptor (AR) expression is an independent unfavorable prognostic factor in gastric cancer. J Cancer Res Clin. 2004; 130(5):253-258.

12. Miyamoto $H$, Yang Z, Chen YT, Ishiguro H, Uemura H, Kubota Y, Nagashima Y, Chang YJ, Hu YC, Tsai MY, Yeh S, Messing EM and Chang C. Promotion of bladder cancer development and progression by androgen receptor signals. J Natl Cancer Inst. 2007; 99(7):558-568.

13. Fang Z, Zhang T, Dizeyi N, Chen S, Wang HY, Swanson KD, Cai CM, Balk SP and Yuan X. Androgen Receptor Enhances p27 Degradation in Prostate Cancer Cells through Rapid and Selective TORC2 Activation. J Biol Chem. 2012; 287(3):2090-2098.

14. Ha S, Ruoff R, Kahoud N, Franke TF and Logan SK. Androgen receptor levels are upregulated by Akt in prostate cancer. Endocr Relat Cancer. 2011; 18(2):245-255.

15. Bagchi G, Hurst $\mathrm{CH}$ and Waxman DJ. Interactions of methoxyacetic acid with androgen receptor. Toxicol Appl Pharmacol. 2009; 238(2):101-110.

16. Song G, Ouyang GL and Bao SD. The activation of Akt/ PKB signaling pathway and cell survival. J Cell Mol Med. 2005; 9(1):59-71.

17. Edwards LA, Thiessen B, Dragowska WH, Daynard T, Bally MB and Dedhar S. Inhibition of ILK in PTEN-mutant human glioblastomas inhibits $\mathrm{PKB} / \mathrm{Akt}$ activation, induces apoptosis, and delays tumor growth. Oncogene. 2005; 24(22):3596-3605.

18. Shin JY, Kim JO, Lee SK, Chae HS and Kang JH. LY294002 may overcome 5-FU resistance via downregulation of activated $\mathrm{p}$-AKT in Epstein-Barr viruspositive gastric cancer cells. BMC Cancer. 2010; 10.

19. Luo BH, Xiong F, Wang JP, Li JH, Zhong M, Liu QL, Luo GQ, Yang XJ, Xiao N, Xie B, Xiao H, Liu RJ, Dong CS, Wang KS and Wen JF. Epidermal Growth FactorLike Domain-Containing Protein 7 (EGFL7) Enhances EGF Receptor-AKT Signaling, Epithelial-Mesenchymal Transition, and Metastasis of Gastric Cancer Cells. PLoS One. 2014; 9(6):e99922.

20. Wang M, Zhang J, Spinetti G, Jiang LQ, Monticone R, Zhao D, Cheng L, Krawczyk M, Talan M, Pintus G and Lakatta EG. Angiotensin II activates matrix metalloproteinase type II and mimics age-associated carotid arterial remodeling in young rats. Am J Pathol. 2005; 167(5):1429-1442.

21. Deryugina EI and Quigley JP. Matrix metalloproteinases and tumor metastasis. Cancer Metastasis Rev. 2006; 25(1):9-34.

22. Parsons SL, Watson SA, Collins HM, Griffin NR, Clarke PA and Steele RJ. Gelatinase (MMP-2 and -9) expression in gastrointestinal malignancy. $\mathrm{Br} \mathrm{J}$ Cancer. 1998; 78(11):1495-1502.

23. Song G, Ouyang G, Mao Y, Ming Y, Bao S and $\mathrm{Hu}$ T. Osteopontin promotes gastric cancer metastasis by augmenting cell survival and invasion through Aktmediated HIF-1alpha up-regulation and MMP9 activation. J Cell Mol Med. 2009; 13(8b):1706-1718.

24. Ma WL, Lai HC, Yeh S, Cai X and Chang C. Androgen receptor roles in hepatocellular carcinoma, fatty liver, cirrhosis and hepatitis. Endocr Relat Cancer. 2014; 21(3):R165-182.

25. Slattery ML, Sweeney C, Murtaugh M, Ma KN, Caan BJ, Potter JD and Wolff R. Associations between vitamin $\mathrm{D}$, vitamin $\mathrm{D}$ receptor gene and the androgen receptor gene with colon and rectal cancer. Int J Cancer. 2006; 118(12):3140-3146.

26. Yerramilli-Rao P, Garofalo O, Whatley S, Leigh PN and Gallo JM. Androgen-controlled specific gene expression in neuroblastoma cells. J Neurol Sci. 1995; 129 Suppl:131-135.

27. Gan L, He J, Zhang X, Zhang YJ, Yu GZ, Chen Y, Pan J, Wang JJ and Wang X. Expression profile and prognostic role of sex hormone receptors in gastric cancer. BMC Cancer. 2012; 12.

28. Yuan X and Balk SP. Mechanisms mediating androgen receptor reactivation after castration. Urol Oncol. 2009; 27(1):36-41.

29. Wu L, Runkle C, Jin HJ, Yu J, Li J, Yang X, Kuzel T, Lee $\mathrm{C}$ and $\mathrm{Yu}$ J. CCN3/NOV gene expression in human prostate cancer is directly suppressed by the androgen receptor. 
Oncogene. 2014; 33(4):504-513.

30. Gao L, Schwartzman J, Gibbs A, Lisac R, Kleinschmidt R, Wilmot B, Bottomly D, Coleman I, Nelson P, McWeeney $\mathrm{S}$ and Alumkal J. Androgen receptor promotes ligandindependent prostate cancer progression through c-Myc upregulation. PLoS One. 2013; 8(5):e63563.

31. Sharma NL, Massie CE, Ramos-Montoya A, Zecchini V, Scott HE, Lamb AD, MacArthur S, Stark R, Warren AY, Mills IG and Neal DE. The androgen receptor induces a distinct transcriptional program in castration-resistant prostate cancer in man. Cancer Cell. 2013; 23(1):35-47.

32. Thomas C, Zoubeidi A, Kuruma H, Fazli L, Lamoureux F, Beraldi E, Monia BP, MacLeod AR, Thuroff JW and Gleave ME. Transcription factor Stat5 knockdown enhances androgen receptor degradation and delays castrationresistant prostate cancer progression in vivo. Mol Cancer Ther. 2011; 10(2):347-359.

33. Wang Y, Kreisberg JI and Ghosh PM. Cross-talk between the androgen receptor and the phosphatidylinositol 3-kinase/ Akt pathway in prostate cancer. Curr Cancer Drug Targets. 2007; 7(6):591-604.

34. Lin HK, Wang $\mathrm{L}, \mathrm{Hu} \mathrm{YC}$, Altuwaijri S and Chang C. Phosphorylation-dependent ubiquitylation and degradation of androgen receptor by Akt require Mdm2 E3 ligase. Embo J. 2002; 21(15):4037-4048.

35. Hanna SC, Krishnan B, Bailey ST, Moschos SJ, Kuan PF, Shimamura T, Osborne LD, Siegel MB, Duncan LM, O’Brien ET, 3rd, Superfine R, Miller CR, Simon MC, Wong KK and Kim WY. HIF1alpha and HIF2alpha independently activate SRC to promote melanoma metastases. J Clin Invest. 2013; 123(5):2078-2093.

36. Lee SJ, Kim WJ and Moon SK. Role of the p38 MAPK signaling pathway in mediating interleukin-28A-induced migration of UMUC-3 cells. Int J Mol Med. 2012; 30(4):945-952.

37. Rahman M, Miyamoto $\mathrm{H}$ and Chang C. Androgen receptor coregulators in prostate cancer: mechanisms and clinical implications. Clin Cancer Res. 2004; 10(7):2208-2219.

38. Hara T, Miyazaki H, Lee A, Tran CP and Reiter RE. Androgen receptor and invasion in prostate cancer. Cancer Res. 2008; 68(4):1128-1135.

39. Wang X, Lee SO, Xia S, Jiang Q, Luo J, Li L, Yeh S and Chang C. Endothelial cells enhance prostate cancer metastasis via IL-6-->androgen receptor-->TGF-beta->MMP-9 signals. Mol Cancer Ther. 2013; 12(6):10261037.

40. Japanese Gastric Cancer A. Japanese Classification of Gastric Carcinoma - 2nd English Edition. Gastric Cancer. 1998; 1(1):10-24.

41. Lauren P. THE TWO HISTOLOGICAL MAIN TYPES OF GASTRIC CARCINOMA: DIFFUSE AND SO-CALLED INTESTINAL-TYPE CARCINOMA. AN ATTEMPT AT A HISTO-CLINICAL CLASSIFICATION. Acta Pathol Microbiol Scand. 1965; 64:31-49. 